\title{
HERNANDO DE SOTO E A SUA TENTATIVA DE SOLUCIONAR O MISTÉRIO DO DESENVOLVIMENTO
}

\author{
Laura Coutinho
}

\section{RESENHA}

DE SOTO, Hernando. The other Path. Nova York: Harper \& Row PUBLISHERS, 1989.

Books, 2000

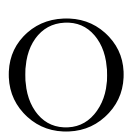
papel das instituições no desempenho da economia tem sido objeto de um intenso debate, que vem se desenrolando nas últimas décadas. Não que o tema seja novo, já que a maior parte dos autores identifica a obra de Max Weber como a matriz teórica das teorias institucionalistas atuais. ${ }^{1}$ A partir da década de 1960, no entanto, em decorrência, em grande medida, das ideias e experiências de economistas como Ronald Coase e Douglass North, esse debate tomou um novo fôlego e ganhou lugar de destaque na agenda internacional. Como avalia
Trubek, ${ }^{2}$ a importância que hoje se dá ao Direito é resultado da "descoberta", pelos economistas, da relevância e da influência da estrutura institucional na economia. A partir daí, organismos internacionais de combate à pobreza passam a estimular e, muitas vezes, a condicionar sua ajuda à adoção de medidas de reengenharia institucional.

A obra do economista Hernando De Soto, objeto de minha análise neste texto, insere-se, portanto, em um contexto muito mais amplo de estudos acadêmicos e empíricos sobre a função das instituições, ${ }^{3}$ muito embora sua 
maior contribuição se dê em uma área bastante particular, ou seja, nas discussões sobre as razões pelas quais programas de regularização fundiária devem ser adotados como medidas de promoção ao desenvolvimento.

De Soto é autor de dois livros dedicados à compreensão do subdesenvolvimento e à elaboração de propostas para seu combate. No primeiro deles, The Other Path, De Soto relata a experiência que ele e um grupo de economistas realizaram em Lima, no Peru, a fim de explicar por que tantos empreendedores se mantêm na informalidade e o quanto se perde com isso. No segundo, The mistery of capital, De Soto busca explicar por que as tentativas de fomento ao desenvolvimento costumam fracassar e, na sequência, oferece sua alternativa às políticas comuns.

Em regra, tanto as análises quanto as críticas ao pensamento de De Soto concentram-se no seu segundo livro. Isso se dá, em parte, porque The mystery of capital é o seu livro de maior sucesso, mas também, e principalmente, porque é nele que De Soto detalha seu plano de combate o subdesenvolvimento e dá a sua contribuição original a este debate, ao afirmar que tais iniciativas só serão bemsucedidas se forem capazes de reconhecer os arranjos informais que dominam, segundo ele, grande parte das economias dos países subdesenvolvidos.

Ocorre que a maior parte das ideias desenvolvidas em The mistery of the capital são fruto ou elaborações feitas a partir das experiências relatadas em The other path. Por esta razão, optei por analisar as duas obras em conjunto. A meu ver, a adoção desta metodologia traz inúmeros ganhos, pois não só permite a melhor compreensão do pensamento de De Soto, como o torna mais coerente. De fato, as ideias expostas por De Soto em The mistery of capital só fazem sentido se partirmos do pressuposto de que não só há uma enorme economia informal, mas que a informalidade é fruto da ineficiência das instituições, como ele afirma em The other path. O foco desta resenha estará, portanto, em um primeiro momento, nas observações que De Soto faz, em The Other Path, sobre as complexas relações econômicas e sociais existentes dentro da economia informal, para depois se concentrar nas soluções por ele propostas em The mistery of capital.

\section{O DIAGNÓsTICO}

A originalidade do pensamento de De Soto está na forma como ele conecta o fracasso da lei e das instituições jurídicas ao fracasso econômico. Em linhas muito simples, o que afirma De Soto (2000, p. 16) é que países pobres são pobres porque não conseguem enxergar sua própria riqueza, já que, segundo as estimativas do autor, $80 \%$ de sua população vive à margem da economia formal e longe, consequentemente, das estatísticas oficiais. Todo seu exercício visa demonstrar, portanto, que o combate ao subdesenvolvimento deve passar, necessariamente, por uma mudança na forma como esses países lidam institucionalmente com sua população mais pobre.

O ponto de partida de De Soto é o seu inconformismo com as justificativas 
usuais dadas para explicar o subdesenvolvimento. Segundo ele, todas elas partem de ideias preconceituosas, como a de que a cultura latino-americana não privilegia o espírito empreendedor ou de que a herança colonial ainda é demasiadamente forte, impedindo o crescimento econômico. Mais do que tudo, no entanto, De Soto (1989, p. xxiii) desconfia da noção dominante de que haja uma imensa massa de pessoas vivendo na mais absoluta miséria. Para ele, a informalidade não é sinônimo, necessariamente, de pobreza. O autor afirma que há uma similitude entre a situação atual enfrentada pelos países subdesenvolvidos e aquela enfrentada pelos países europeus e pelos Estados Unidos no passado (DE SOTO, 2000, p. 105-107). Em todos os casos, continua ele, houve uma resistência da população urbana em receber os migrantes, a qual se traduziu no estabelecimento de uma série de empecilhos à fixação desses na cidade, que vão da adoção de políticas explícitas de proibição da migração à criação de uma enorme burocracia para o estabelecimento de tais indivíduos. O resultado é, porém, sempre um: essa população é condenada a viver na ilegalidade. Isso não significa, no entanto, que ela não esteja economicamente ativa.

Para comprovar suas suspeitas, De Soto (1989, p. 133) imaginou um experimento razoavelmente simples: verificar quais são os procedimentos necessários para que um pequeno empreendedor regularize seu negócio perante as autoridades peruanas. Com este fim, um grupo de economistas do Instituto para
Liberdade e Democracia, o qual De Soto preside, fez alguns estudos de casos e até tentou, de fato, iniciar uma pequena confecção.

Os resultados foram espantosos, mas não surpreendentes, e confirmaram ao menos parte das ideias de De Soto. Para iniciar a pequena confecção, os economistas gastaram 289 dias e US\$ 149,00 em taxas (DE SOTO, 1989, p. 134). Se considerarmos o período em que não se produziu, foram consumidos US\$1.231,00 na regularização do empreendimento. As demais experiências revelaram resultados parecidos, mas outra questão surgiu: se seria, realmente, como também acredita o senso comum, mais vantajoso para esta parte da população permanecer na ilegalidade.

De Soto tenta, então, compreender quais são as perdas que um empreendedor informal enfrenta por não poder contar com a proteção da lei. De acordo com o autor, para evitar ser detectado, um empreendedor informal precisa manter seu negócio em pequena escala. Ele não pode fazer propaganda e ocasionalmente é obrigado a pagar propinas a agentes públicos, a fim de não sofrer sanções legais. Por outro lado, ele não vive completamente fora do sistema tributário, já que há uma série de tributos indiretos que ele também deve suportar, embora não possa contar com vários dos benefícios que o Estado proporciona. Por fim, a desobediência de regras trabalhistas, que poderia se traduzir em aparente vantagem, resulta também em perdas, uma vez que o informal só consegue contratar mão de obra pouco qualificada. 
Além desses custos, que De Soto identifica como custos para se manter na informalidade, há aqueles que o informal deve suportar por não poder contar com a proteção legal. A lei tem tríplice função quando se pensa em um empreendimento econômico. Ela protege a propriedade, cria mecanismos de enforcement de contratos e um sistema de responsabilização civil. Ao ficar "fora da lei”, o informal não pode se valer de nenhuma destas vantagens. Não possuindo títulos de propriedade, ele não pode utilizar seu imóvel para obter crédito. Há, ainda, um efeito secundário. A insegurança da posse faz que os informais não invistam nos imóveis nem se sintam estimulados a poupar para neles introduzir melhorias (DE SOTO, 1989, p. 158).

Sem contar com o Estado para fazer valer o contratado, os informais preferem realizar negócios somente com aqueles com que mantêm relações diretas, o que reduz drasticamente as suas possibilidades de contratação. Além disso, os informais não podem fazer seguros ou se valer de outros instrumentos facilitadores do comércio, como venda de ações ou títulos de crédito. Finalmente, a impossibilidade de se utilizarem regras de responsabilização civil cria temores entre os empresários, o que sempre se traduz na redução de investimentos.

Isso não significa, como observa De Soto, que os informais consigam sobreviver sem alguns destes instrumentos. Em regra, De Soto relata que eles desenvolvem sistemas paralelos, adaptando regras dos sistemas oficiais de acordo com as suas necessidades. Pendências são resolvidas por "tribunais" informais, aplicando-se regas costumeiras. Criam-se milícias responsáveis por fazer valer a lei e aplicar penas e repartições de registro que fornecerão as informações necessárias nos casos de disputa por terra.

A descrição fornecida por De Soto é bastante condizente com o que qualquer um pode observar em centros urbanos como Rio de Janeiro e São Paulo. É muito difícil negar que exista grande atividade econômica fora do mundo oficial. De acordo com dados do IBGE, há no Brasil 10.335.962 empresas informais, que empregam 13.860.868 trabalhadores; $94 \%$ destas empresas não utilizaram sistema de crédito no período de três meses imediatamente anterior à pesquisa. ${ }^{4} \mathrm{~A}$ substituição do Estado por outras organizações, muitas vezes criminosas, também parece inquestionável. O problema está no passo seguinte que De Soto dá, ou seja, na solução proposta ao problema.

\section{O REMÉDIO}

Para podermos enfrentar a informalidade, alega De Soto (2000, p. 108-135), devemos olhar o passado. Como já dito, segundo ele, a situação enfrentada pelos países latino-americanos e por outras nações subdesenvolvidas na atualidade é semelhante à que a Europa e os Estados Unidos já enfrentaram. A onda migratória que leva hoje a população a procurar os grandes centros urbanos do Terceiro Mundo é igual à onda migratória que se seguiu à Revolução Industrial ou à que se deu nos Estados Unidos durante sua 
colonização. Além da hostilidade dos antigos habitantes, essa população é obrigada a lidar com o fato de que as cidades e as instituições existentes não foram pensadas para lidar com a necessidade de uma massa tão grande de pessoas.

De Soto conclui, assim, que o subdesenvolvimento deve ser combatido pela reforma institucional, mas que o modelo inspirador da maioria das primeiras iniciativas com este fim era equivocado, já que calcado no modelo vigente, e não no modelo adotado pelos países subdesenvolvidos no momento em que enfrentaram os mesmos problemas que enfrentam os países subdesenvolvidos na atualidade.

A partir de uma análise sobre a evolução da legislação sobre terras nos Estados Unidos, De Soto desenha uma possível saída para os países pobres: o sistema oficial deve incorporar os costumes e as práticas vigentes. Esta solução parece ser do mais absoluto bom senso: se a lei não consegue atender às necessidades dos cidadãos dos quais regula a vida, ela deve se adaptar - e não aqueles. O problema das iniciativas desenvolvimentistas que visavam à reforma institucional foi o de ignorar a realidade de cada um dos países, buscando impingir, como adverte Trubek, um modelo-padrão a uma centena de países diferentes.

De Soto não enfrenta, no entanto, a questão do quanto se pode ceder nesta institucionalização dos costumes, a não ser por uma simples ressalva de que devemos copiar os acertos e evitar os erros cometidos neste processo, pelas nações hoje desenvolvidas. Nos Estados
Unidos, por exemplo, a Lei de Terras ignorou os flagrantes desrespeitos às divisas originais das reservas florestais e indígenas e legalizou a propriedade particular sobre áreas originalmente destinadas àquele fim. De Soto minimiza ou ignora o dilema que uma opção tal deveria enfrentar. Ainda que a concessão de títulos e a regularização da posse sejam capazes de trazer crescimento econômico, será que elas, de fato, poderão se traduzir em efetivos ganhos sociais? Amartya Sen, que também crê na relevância das instituições para o sucesso econômico, nega este caráter estritamente instrumental da reforma institucional e afirma que o crescimento econômico, isto é, a melhora da economia, não pode se dar com prejuízo do bem-estar da população; mas sobre isso De Soto nada fala.

De Soto também não distingue simples complicações burocráticas, que estão, de fato, por trás de muitas leis, de reais preocupações que orientam a elaboração de um ordenamento jurídico. No caso específico da ocupação do solo, que é objeto central das análises de De Soto, isso é ainda mais evidente. Restrições urbanísticas, critérios rigorosos para o loteamento de áreas, proibição de utilização de áreas ribeirinhas ou de encostas não decorrem da insensibilidade do Estado em relação aos problemas de seus cidadãos. Pelo contrário, essas ações quase sempre visam garantir a qualidade de vida dos seus habitantes. Abrir mão delas sob o pretexto de garantir o crescimento econômico pode não ser a opção que melhor atenda à 
população, especialmente em longo prazo. Se a observação da experiência americana demonstra que o seu sucesso econômico passou, em um determinado momento, pela simples consolidação e aceitação, pelo poder estatal, dos costumes, ela pode servir também para demonstrar que certos erros são irremediáveis e que seu preço deverá ser pago em algum momento. Nesse sentido, pensando-se em termos culturais e ambientais e ficando só no exemplo do próprio De Soto, não se podem ignorar as graves consequências da ocupação desordenada do solo nos Estados Unidos, que levou à morte grande parte da população nativa e dizimou áreas verdes. A questão a qual De Soto não responde é se os então governantes americanos teriam escolhido regularizar tal situação se eles tivessem o conhecimento que hoje temos dos reais efeitos de sua opção.

De Soto minimiza, igualmente, as advertências que teóricos do Direito e Desenvolvimento fazem sobre a possibilidade de se transportarem instituições de um país a outro, sejam elas antigas, sejam elas contemporâneas.

Em síntese, apesar de sua inegável contribuição à compreensão da intricada relação entre lei e pobreza e, mais do que tudo, por sua tentativa honesta de olhar essa relação pelo ângulo daqueles que sofrem as consequências da lei, e não pelo ângulo daqueles que a criam, Hernando De Soto não conseguiu superar a questão central que o Estado moderno enfrenta, que é a de conciliar crescimento econômico, desenvolvimento social e preocupações ambientais.

\section{NOTAS}

1 David Trubek (RODRIGUEZ, 2009, pp. 1 50), no artigo Max Weber sobre o direito e a ascensão do capitalismo, demonstra a relação direta entre a obra do sociólogo e as teorias institucionalistas e desenvolvimentistas atuais.

2 Entrevista concedida à Revista DIREITO GV (RODRIGUEZ, 2007).
3 Ainda de acordo com Trubek, basta uma rápida observação no site do Banco Mundial para se perceber a magnitude e importância dada às instituições nas políticas econômicas.

4 Ver Boletim Comunicação Social de 19.05.2005, do Instituto Brasileiro de Geografia e Estatística (IBGE). Disponível em: <www.ibge.gov.br/home/presidencia/ noticias / noticia_impressao.php?id_noticia $=366>$. 


\section{REFERÊNCIAS BIBLIOGRÁFICAS}

DE SOTO, Hernando. The other path. Nova York: Harper \& Row Publishers, 1989. The mistery of capital. Nova York: Basic Books, 2000 .

RODRIGUEZ, José Rodrigo (Org.). O novo direito e desenvolvimento: presente, passado e futuro. Textos selecionados de David M. Trubek. São Paulo: Saraiva, 2009.

$$
\text { (coord.). O novo direito e }
$$

desenvolvimento. Entrevista com David Trubek.

Revista DIREITO GV. São Paulo: DIREITO GV, v. 3, n. 2, jul-dez 2007, pp. 305-330.

\section{Laura Coutinho}

Rua Goitacaz, 71, ap. 21 Santa Cecília - 01232-030 São Paulo - SP - Brasil lauracoutinholayahoo.com.br
MESTRANDA EM DIREITO E DESENVOLVIMENTO NA DIREITO GV 